\title{
Research on Precise Poverty Alleviation Mode Based on Big Data Thinking
}

\author{
Zhao xu \\ School of Economics and Management, Beijing Jiaotong University, Beijing, China \\ Email: zhaoxutdwj@163.com
}

Keywords: big data; precise poverty alleviation; internet

\begin{abstract}
Facing the coming of the goal of completing the building of a moderately prosperous society in all respects by 2020 , poverty alleviation work must be changed from extensive poverty alleviation to taking targeted measures in poverty alleviation. Under this circumstance, big data and internet provided technical support. Based on big data thinking, the paper analyzes the support mechanism of big data to precise poverty alleviation and present the mode of precise poverty alleviation which consists of three parts: one system, two subjects and four mechanisms and demonstrate it.
\end{abstract}

\section{基于大数据思维的精准扶贫模式研究}

\author{
赵旭 \\ 北京交通大学经济管理学院, 北京, 中国 \\ Email: zhaoxutdwj@163.com
}

关键词: 大数据; 精准扶贫; 互联网

中文摘要. 面临2020年全面建成小康社会节点的迫近，扶贫工作必须由 “大水漫灌” 的粗放 扶贫向 “精准滴灌” 的精准扶贫转变, 而大数据和互联网技术的发展成熟恰为精准扶贫提供 了技术保障。本文基于大数据思维, 分析了大数据对于精准扶贫的支持机理, 提出了 “一个 系统、两个主体、四个机制”的精准扶贫模式, 并加以论证。

\section{1. 引言}

中国 30 多年来共减少 6.6 亿贫困人口, 是世界奇迹。但是, 我国还有约 7000 万人生活在贫 困之中, 要完成 2020 年要全面建成小康社会的目标, 每年要减少贫困人口 1400 万人, 我国扶 贫开发工作已进入啃硬骨头、攻坚拔寨的冲刺期。由于各省乃至全国都没有建立统一的扶贫 信息系统，长期以来我国贫困居民底数不清、情况不明、扶贫针对性不强、扶贫资金和项目 指向不准的问题较为突出, 真正的一些贫困农户和贫困居民并没有得到帮扶, 现实问题迫切 要求精准扶贫。2015年6月, 习近平全面阐述了 “精准扶贫” 的概念, 提出 “六个精准” , 即 “扶贫对象精准、项目安排精准、资金使用精准、措施到户精准、因村派人精准和脱贫成效 精准”。大数据的发展迅猛, 为精准扶贫提供了切实的技术保障。“大数据时代” 将伴随着

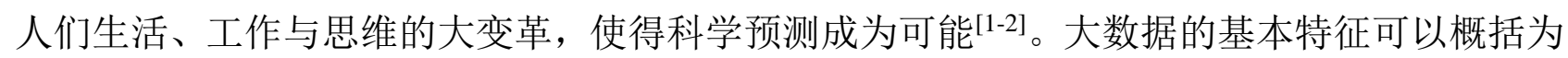
“5V” 特征, 即Volume、Velocity、Variety、Value和Veracity ${ }^{[3]}$ 。大数据的蓬勃发展符合 了精准扶贫的现实需求, 因此探讨大数据促进精准扶贫的作用机理, 研究大数据助力精准扶 贫的具体模式具有重要现实意义。 


\section{2. 大数据支持精准扶贫的机理}

扶贫领域的研究颇多, 在具体的救助机理机制方面, 比较有代表性的是路锦非, 其研究 了支出型贫困家庭的扶贫救助机制 ${ }^{[4]}$ 。大数据是一种新兴业态, 其具体应用刚起步, 尚不能 进行实证来分析大数据的具体作用效果, 因而, 基于大数据视角研究扶贫问题的较少。郑瑞 强, 曹国庆 (2015) 基于大数据思维方式, 总结了当前扶贫工作的挑战, 提出 “十三五” 期 间扶贫策略 ${ }^{[5]}$ 。除此之外, 学术界并未对大数据运用到精准扶贫领域的作用机制、应用模式 进行过研究。本文基于这一背景, 指出大数据支持精准扶贫的机理, 探索建立基于大数据思 维的精准扶贫模式。

\section{1 原理支持}

在小数据时代，随机性的样本抽样导致长期以来扶贫工作中 “谁是贫困居民”、“贫困 原因是什么”、“怎么针对帮扶”、“帮扶效果怎样” 等问题较为突出。而当运用 “大数据” 的思维和技术, 拥有 (几乎) 全部的贫困人口数据时, 就能从不同角度, 深入细致地观察和 研究数据的方方面面, 从而做出科学合理的决策。

\section{2 数据积累支持}

精准扶贫工作实质上是政府、社会与扶贫对象等多元主体行为互动作用的过程, 政府数 据主要包括扶贫对象规模与分布、扶贫资源结构与绩效等, 这些数据囊括了各贫困村、贫困 户的具体情况和贫困原因, 为大数据的信息搜集夯实了基础; 物理空间数据主要指政府职能 部门对于部分扶贫项目的实时监测数据; 网络数据较为丰富, 既包括多元主体通信、社会网 络等日常生产数据, 也包括扶贫项目建管、金融服务、服务购买、文本图片、视频音频等各 种媒体信息。

\section{3 技术保障支持}

推行大数据扶贫管理模式, 就是在综合利用遥感遥测、网络宽带、多媒体及虚拟仿真等 数字技术的基础上, 深入分析贫困地区产业、人口、环境等相关数据, 整合农村、交通、环 境、基础设施等领域的信息, 了解和掌握贫困对象的实际需求和利益诉求, 实现扶贫工作的 精准定位、动态管理和科学预测。

1 ）精准定位。精准扶贫的首要问题就是定位扶贫对象，运用 “大数据”思维，可以实现 对每个贫困村、贫困户建档立卡, 将扶贫对象的基本资料、动态情况录入到系统, 建立起一 整套的扶贫对象网络信息系统及数据库，并通过统计技术系统模拟出扶贫对象的贫困程度。

2) 动态管理。在进行精准定位后, 必然面临的是信息化管理, 对扶贫对象进行动态管理, 对扶贫项目进行动态跟踪, 对扶贫资金进行动态监督, 这种动态调整管理, 可以极大克服以 往瞄准目标静态、滞后的弱点。这种动态管理的方式可以实现扶贫对象有进有出, 不断缩减 贫困户数量; 可以对实施跟踪扶贫项目的进展和困难, 发现问题, 解决问题; 可以准确管理 每一笔资金的流向，保证专款专用，落到实处。

3 ) 科学预测。大数据的核心就是预测, 扶贫对象的动态管理使我们实现了从数据收集到 数据分析的转变, 接下来就是从大数据中预测扶贫需求, 预判扶贫问题, 通过大数据系统数 据和科学方法的合理预测, 我们可以准确把握扶贫对象的需求, 正确处理扶贫工作中存在的 问题, 从而有针对性地引导资金流的方向, 解决贫困农户最切身的问题。确保 “好钢用在刀 刃上”，避免 “手榴弹炸跳蚤” 的现象，避免资源浪费，提高扶贫效率。

\section{3. 基于大数据思维的精准扶贫模式}

基于大数据的思维，在 “互联网+” 的时代背景下，本文提出基于大数据思维的精准扶贫 模式, 简洁概括为 “一个系统、两个主体、四个机制”。“一个系统” 是基础, 即政府在对 
贫困户建档立卡的过程中逐步建立大数据扶贫管理系统, 实现扶贫工作的网络化、科学化、 精准化、动态化; “两个主体” 是核心, 指政府和企业两个主体的联合, 政府建立大数据扶 贫管理系统和贫困户大数据中心, 企业在市场供给侧建立生产者大数据和农产品大数据, 在 需求侧建立消费者大数据, 通过需求侧和供给侧的对接确保特色产品的精准销售, 通过需求 侧对贫困户生产者的政策倾斜实现精准扶贫; “四个机制” 是保障，即通过股权收益扶贫制、 脱贫工作责任制、社会保障淣底制和扶贫投诉巡查制保障模式的平稳运行，如图1：

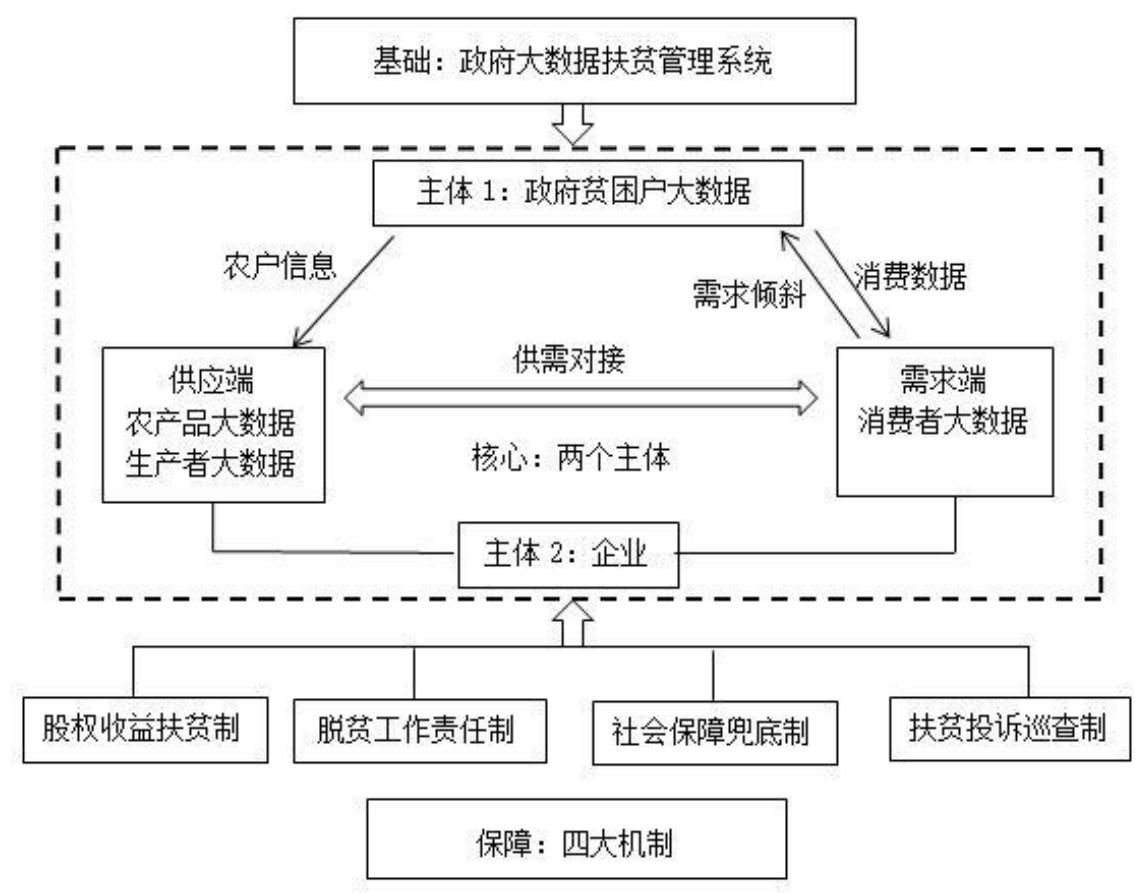

图1 大数据思维下的精准扶贫模式

\section{1 基础: 政府主导的大数据扶贫管理系统}

各省应适时建立大数据扶贫管理系统, 为全国建立扶贫系统提供基础, 为精准扶贫的顺 利开展奠定基石，扶贫管理系统可以概括为 “一个平台、两个系统、四个中心”。

1）“一个平台”。即精准扶贫大数据管理平台，分为村、镇、县、市、省级组织管理架 构。由省建设统一的应用软件系统、制定规范标准, 各级管理建设所需的扶贫工作人员配置、 软硬件配置等有关经费纳入各级财政。

2）“两个系统”。即手机和电脑两个管理软件系统。软件系统分别设置扶贫方面的数据 采集、档案录入、项目申报、帮扶单位推荐、扶贫解答等多项专栏及服务功能, 实现贫困信 息、需求信息与社会各界的扶贫资源、帮扶意愿等对接共享, 整合农业生产、农业科技、市 场价格等涉农信息资源，为农民提供适用的信息服务，解决贫困农民生产生活遇到的问题。 同时, 实时在线采集扶贫数据、分类数据、在线申报扶贫项目等数据, 所有数据分类后传输 汇总至各级大数据中心，达到数据传输在线同步。

3）“四个中心”。即采集、申报、评审和大数据中心。采集中心: 由省建立统一的表格 化数据采集标准体系和对应的数据采集模型, 各级中心匹配相应扶贫工作人员、采集设备; 申报中心: 省一级建立统一的申报标准体系和对应的申报模型, 各级中心匹配相应扶贫项目 申报人员; 评审中心: 扶贫申报项目评审设置镇、县、市、省四级审核管理机制, 省级管理 建立统一的扶贫项目评审标准体系和评审模型; 大数据中心: 县、市、省级管理下设各级大 数据中心, 建立县、市、省级数据库系统, 实时备份数据及定期更新、升级数据库系统。 


\section{2 核心: 两个主体}

扶贫工作政府和企业共同发力。政府应在发掘本地区资源、产品特色的基础上，引导以 企业为代表的社会力量的参与, 发展高效特色农业, 促进产业升级, 培育农产品加工业、乡 村旅游、农村电商等特色产业。企业层面, 在供应侧建立农产品大数据和生产者大数据, 在 需求侧建立消费者大数据, 实现农产品供给和需求的无缝对接; 政府依托于大数据扶贫系统, 联合生产者大数据，企业即可设计向贫困人口倾斜的农产品生产供应链，实现精准扶贫。

\section{3 保障: 四大机制}

1）股权收益扶贫制。上世纪90年代的城乡企业蓬勃发展，产权的合理分配正是促进这一 趋势的重要保障, 涌现出永钢、得利斯等为代表的一批乡镇企业, 这为各地提供了思路: 农 村要充分利用本地区的优势资源，探索以资源换股权的机制。各地方政府要深化农村产权制 度改革，建立股权量化、资产收益扶贫机制，引导贫困户将耕地、林地、个人财产和集体 “三 资”股权，采取入股、委托经营、合作经营等方式，增加贫困农户的财产性收益。

2）脱贫工作责任制。对干部实行脱贫责任制，适时实施挂职干部下村承包贫困户脱贫工 作机制, 按不同职级承包数量不等的贫困户脱贫任务, 实行挂职干部带资帮扶与奖惩制相结 合，扶贫工作与职务升迁相结合的政策，改变政绩考核片面以GDP衡量的方式。

3）社会保障自底制。搭建政府部门救助资源、社会组织救助项目与贫困农户救助需求相 对接的信息平台, 鼓励、引导、支持社会组织、企事业单位和爱心人士开展慈善救助, 强化 民政、残联、妇联、红十字会组织慈善救助的职能, 逐年提高农村低保保障标准和特困人员 供养标准，对符合农村低保条件的困难群众实行应保尽保。

4）扶贫投诉巡查制。为确保扶贫资金的正确使用、扶贫项目的顺利进行、扶贫工作的平 稳推进，建立扶贫投诉巡查机制十分必要巡查对象主要包括两个方面，一是对扶贫资金使用 扶贫项目落实的巡查，二是对惠农政策落实的巡查。

\section{4 结论}

本文基于大数据的背景提出的精准扶贫模式在一些地方在精准扶贫模式方面已经开始了 探索，比如贵州省黔南州携手互联网企业广州奇码，丹寨县万达集团 “企业包县扶贫” 模式。 目前, 学术界对于精准扶贫模式的研究尚处在初始阶段, 各地区也都有着自身特色, 因此, 精准扶贫并没有固定的模式可以遵循。随着大数据在扶贫工作中的深入应用, 探讨精准扶贫 的作用效果成为必然，从理论上构筑“扶贫精准度”测量模型将会成为一种研究方向。

\section{References}

[1] Viktor Mayer-Schonberger, Big Data: A Revolution That Will Transform How We Live, Work and Think[M].John Murray Publishers Ltd, 2013.

[2] Marijn Janssen, Factors influencing big data decision-making quality, journal of business research, vol.70, pp.338-345, 2017.

[3] Lau, Raymand, Big data commerce, Information \& Management,vol.53,pp.929-933,2016

[4] Lu Jinfei and Cao Yanchun. Macro-analysis and The Mechanism of Salvation on Expenditure Factors of Poverty Family[J].Finance and Trade Research, 2011(2):86-91.(In Chinese)

[5] Zheng Ruiqiang and Cao Guoqing. Research on The Precise Poverty Alleviation Mechanism Based on Big Data Thinking[J].Guizhou Social Sciences, 2015(8):163-168.(In Chinese) 